\title{
6 Lead Standard
}

National Cancer Institute

\section{Source}

National Cancer Institute. 6 Lead Standard. NCI Thesaurus. Code C90350.

An electrocardiogram lead placement on the patient using a six electrode lead set with three standard leads and three aug mented derived leads to elicit an electrical view of the heart. 